\title{
PEMBUATAN BAHAN ACUAN BAKU UNTUK ANALISIS CONTO SEDIMEN SUNGAI AKTIF
}

\section{THE ESTABLISHMENT OF ANALYSIS STANDARD REFERENCE MATERIAL FOR STREAM SEDIMENT SAMPLE}

\author{
Dedeh Dinarsih dan Herry Rodiana Eddy \\ Pusat Sumber Daya Mineral, Batubara dan Panas Bumi \\ dedeh.dinarsih@yahoo.co.id
}

\begin{abstract}
ABSTRAK
Pembuatan bahan acuan baku untuk analisis conto sedimen sungai aktif (standard reference material for stream sediment) merupakan bahan acuan sekunder dalam analisis laboratorium pengujian yang dapat menunjang akurasi serta presisi hasil analisis conto sedimen sungai sesuai SNI ISO/IEC 17025 : 2008 Komite Akreditasi Nasional.

Pemercontoan bahan acuan baku ini dilakukan di wilayah Nagari Surian, Kecamatan Pantai Cermin, serta di wilayah Nagari Air Dingin dan Nagari Kotabaru, Kecamatan Lembah Gumanti, Kabupaten Solok, Provinsi Sumatera Barat dengan metode pengambilan secara acak. Parameter yang dianalisis terdiri dari total seluruh unsur yang dianalisis meliputi tembaga $(\mathrm{Cu})$, timbal $(\mathrm{Pb})$, seng $(\mathrm{Zn})$ dan perak $(\mathrm{Ag})$. Hasil analisis internal dan eksternal/uji banding dengan parameter analisis $\mathrm{Cu}, \mathrm{Pb}, \mathrm{Zn}$ dan $\mathrm{Ag}$, kemudian dilakukan pengolahan data dan ditentukan uji homogenitas, nilai presisi, akurasi, relatif standar deviasi, limit deteksi, uji histogram, uji Dixon, Nilai Z- Scorel (Out-In Lier).
\end{abstract}

Pembuatan bahan acuan baku ini menghasilkan enam jenis conto standar dengan tiga kriteria yaitu nilai kadar rendah, sedang dan tinggi (low, middle and high level) dengan kehalusan 80 mesh dan 150 mesh sampai dengan 200 mesh.

Bahan acuan baku yang mempunyai kehalusan 80 mesh terdiri dari tiga kriteria yaitu kode conto SS.SLK-L1 termasuk kriteria kadar rendah dengan kandungan $\mathrm{Cu} 25,50$ ppm, $\mathrm{Pb} 13,21$ ppm, Zn 44,96 ppm dan Ag 1,26 ppm, kode conto SS.SLK-M1 merupakan bahan acuanbaku kriteria kadar sedang dengan kandungan $\mathrm{Cu} 38,80$ ppm, Pb 16,60 ppm, Zn 70,05 ppm dan Ag 1,70 ppm, sedangkan kode conto SS.SLK-H1 termasuk kriteria kadar tinggi dengan kandungan $\mathrm{Cu} 82,20$ ppm, Pb 39,80 ppm, Zn 95,10 ppm dan Ag 2,08 ppm.

Bahan acuan baku dengan kehalusan 150 mesh sampai dengan 200 mesh terdiri dari tiga macam yaitu kode conto SS.SLK-L2 yang termasuk kriteria kadar rendah dengan kandungan $\mathrm{Cu} 32,70$ ppm, Pb 25,90 ppm, Zn 89,90 ppm dan Ag 1,31 ppm, kode conto SS.SLK-M2 merupakan bahan acuan baku kriteria sedang dengan kandungan $\mathrm{Cu} 44,40 \mathrm{ppm}, \mathrm{Pb} 35,20$ ppm, Zn 14,00 ppm dan Ag 1,70 ppm sedangkan kode conto SS.SLK-H2 termasuk kriteria kadar tinggi dengan kandungan $\mathrm{Cu} 90,90$ ppm, Pb 56,30 ppm, Zn 160,00 ppm dan Ag 2,52 ppm.

Kata kunci: bahan acuan baku, sedimen sungai aktif, analisis laboratorium, Pantai Cermin, Lembah Gumanti

\section{ABSTRACT}

The establishment of stream sediment standard reference material is a secondary reference in the internal quality control of a testing laboratory that can support the accuracy and precision 


\section{MAKALAH ILMIAH}

of stream sediment analysis results as required by the National Accreditation Committee (KAN) listed in SNI ISO/IEC 17025: 2008.

Stream sediment standard reference material sampling was conducted in Nagari Surian Area, Pantai Cermin District and Nagari Air Dingin Area, Gumanti Valley District, Solok Regency, West Sumatera Province with random sampling method. The analyzed parameters consists of total copper $(\mathrm{Cu})$, lead $(\mathrm{Pb})$, zinc $(\mathrm{Zn})$ and silver $(\mathrm{Ag})$. From the results of internal and external analysis/ comparative test with analysis parameters of $\mathrm{Cu}, \mathrm{Pb}, \mathrm{Zn}$, and $\mathrm{Ag}$, data processing were done and the homogenity test, precision value, accuracy, relative standard deviation (RSD), limit of detection, histogram test, Dixon test, Z- Score (Out-In Lier) were determined.

The establishment of stream sediment standard reference material succesfully delivers 6 types of standard samples with 3 kinds of standard work criteria i.e. low, medium and high level with fineness of 80 mesh and 200 mesh.

Stream sediment standard reference material with fineness of 80 mesh consists of three criteria i.e. SS.SLK-L 1 which is categorized into low level criteria with $\mathrm{Cu}$ of $25.50 \mathrm{ppm}, \mathrm{Pb}$ of $13.21 \mathrm{ppm}, \mathrm{Zn}$ of $44.96 \mathrm{ppm}$ and $\mathrm{Ag}$ of $1.26 \mathrm{ppm}$, SS.SLK-M1 is a medium level stream sediment with $\mathrm{Cu}$ of $38.80 \mathrm{ppm}, \mathrm{Pb} 16.60$ of ppm, $\mathrm{Zn}$ of $70.05 \mathrm{ppm}$ and $\mathrm{Ag}$ of $1.70 \mathrm{ppm}$ while SS.SLK-H1 is categorized into high level criteria with $\mathrm{Cu}$ of $82.20 \mathrm{ppm}, \mathrm{Pb}$ of $39.80 \mathrm{ppm}, \mathrm{Zn}$ of $95.10 \mathrm{ppm}$ and $\mathrm{Ag}$ of $2.08 \mathrm{ppm}$.

Stream sediment standard reference material with fineness of 150-200 mesh consists of three criteria i.e. SS. SLK-L2 which is categorized into low criteria with Cu of $32.70 \mathrm{ppm}, \mathrm{Pb}$ of 25.90 ppm, Zn of 89.90 ppm and Ag of 1.31 ppm, SS.SLK-M2 is a medium stream sediment with $\mathrm{Cu}$ of $44.40 \mathrm{ppm}, \mathrm{Pb}$ of $35.20 \mathrm{ppm}, \mathrm{Zn}$ of $14.00 \mathrm{ppm}$ and $\mathrm{Ag}$ of $1.70 \mathrm{ppm}$ while SS.SLK-H2 is categorized into high criteria with $\mathrm{Cu}$ of $90.90 \mathrm{ppm}, \mathrm{Pb}$ of $56.30 \mathrm{ppm}, \mathrm{Zn}$ of $160.00 \mathrm{ppm}$ and Ag of 2.52 ppm.

Keywords: standard reference material, stream sediment, laboratory analysis, Pantai Cermin, Lembah Gumanti

\section{PENDAHULUAN}

Stream Sediment atau sedimen sungai aktif memiliki kandungan unsur sesuai dengan daerah yang dilalui oleh aliran sungai, baik secara alamiah dari mineral yang terkandung dalam batuan/tanah atau berkaitan dengan adanya aktifitas manusia yang menghasilkan buangan unsur tersebut. Unsur dalam batuan atau tanah dapat berinteraksi dengan udara dan air sehingga beberapa unsur larut dalam air dan akan merembes ke dalam daerah aliran sungai. Sebaliknya unsur dalam air dapat mengendap kembali jika keadaan hidrologi dan $\mathrm{pH}$ air berubah.

Kandungan unsur dalam sedimen sungai aktif merupakan gabungan dari kadar unsur dalam mineral yang ada dalam sedimen dan hasil keseimbangan unsur tersebut antara fasa air dan koloid. Satuan batuan yang dilalui aliran anak sungai yang sangat mempengaruhi jenis mineral/fragmen batuan yang terkandung dalam endapan sungai.

Komposisi unsur kimia dalam conto mineral, sedimen sungai aktif dan batuan, sangat heterogen sehingga akan terjadi saling mempengaruhi pada proses reaksi kimia (metode konvensional) dan reaksi fisika (metode instrumen), sehingga akan mempengaruhi respon atau pembacaan pada alat detektor dan pada akhirnya akan mempengaruhi akurasi hasil analisis. Conto baku yang sesuai dengan conto yang dianalisis dapat menghindarkan dari pengaruh pembacaan oleh unsur-unsur lain (efek matrik), sehingga mendapatkan hasil analisis yang akurat. 
Salah satu upaya untuk mendapatkan hasil analisis sedimen sungai aktif yang akurat di laboratorium, selain metode analisis yang digunakan harus valid, juga mutlak diperlukan conto acuan baku sedimen sungai aktif yang telah diketahui kandungannya (Certified Reference Material/CRM) seperti yang dipersyaratkan oleh Komite Akreditasi Nasional (SNI ISO/IEC 17025 : 2008) bahwa laboratorium harus memiliki acuan baku (Reference Material) atau Standard Reference Material (SRM) yang mampu telusur (traceability).

Hasil analisis menjadi salah satu pertimbangan dalam menentukan metode analisis di laboratorium, agar dapat diperoleh data hasil analisis untuk $\mathrm{Cu}, \mathrm{Pb}$, $\mathrm{Zn}$, dan Ag yang akurat.

Akurasi hasil analisis tergantung pada tiga faktor utama yaitu analis yang kompeten, metode yang valid, dan adanya conto standar (Standard Reference Material/SRM. Selama ini conto baku (Standard Reference Material/SRM) yang digunakan diperoleh dari National Bureau of Standards (NBS), National Institute of Standards and Technology (NIST), British Standard (BS), National China of Standards (NCS) dan lainnya, yang selain harganya mahal, pemesanannya juga memerlukan waktu yang lama.

Pembuatan bahan acuan baku untuk analisis conto sedimen sungai aktif (inhouse standard stream sediment), yang selanjutnya disebut pembuatan bahan acuan baku yang bertujuan untuk mendapatkan conto standar sedimen sungai aktif yang dapat dijadikan acuan dan selalu siap digunakan untuk kegiatan analisis conto sedimen sungai di
Laboratorium Pusat Sumber Daya Mineral, Batubara dan Panas Bumi (PSDMBP), sehingga diperoleh hasil analisis yang terjamin/terkendali mutunya dan lebih ekonomis, sehingga kegiatan analisis conto sedimen sungai aktif berjalan lancar dan akurat.

Pengambilan conto pembuatan bahan acuan baku analisis untuk conto sedimen sungai aktif ini dilakukan di Kabupaten Solok, Provinsi Sumatera Barat (Gambar 1). Suprapto (2014) menyatakan daerah ini mempunyai potensi mineralisasi logam besi-tembaga-timbal-seng (Fe-Cu-Pb-Zn), berdasarkan pada kondisi struktur geologi dan litologi (Gambar 2 dan Gambar 3).

Secara geologi daerah Kabupaten Solok berada pada jalur metalogenik Sunda Banda. Batuan penyusun terdiri dari batuan metamorf berumur Perem sampai Trias, batuan terobosan dijumpai berumur PraTersier dan Tersier. Pada batuan Tersier secara stratigrafi di atasnya menumpang batuan sedimen dan vulkanik. Batuan vulkanik Tersier dan Kuarter menutup sebagian besar Daerah Kabupaten Solok dan sekitarnya.

\section{METODOLOGI}

Tahapan pembuatan bahan acuan baku meliputi studi literatur, pemercontoan sedimen sungai, menganalisis conto, dan mengolah data baik di laboratorium internal maupun eksternal. Analisis eksternal dilakukan di delapan laboratorium di luar Laboratorium PSDMBP. Pengolah data hasil analisis tersebut menggunakan metode statistik, seperti; uji Histogram, uji Dixon dan uji Z-Score. 


\section{MAKALAH ILMIAH}

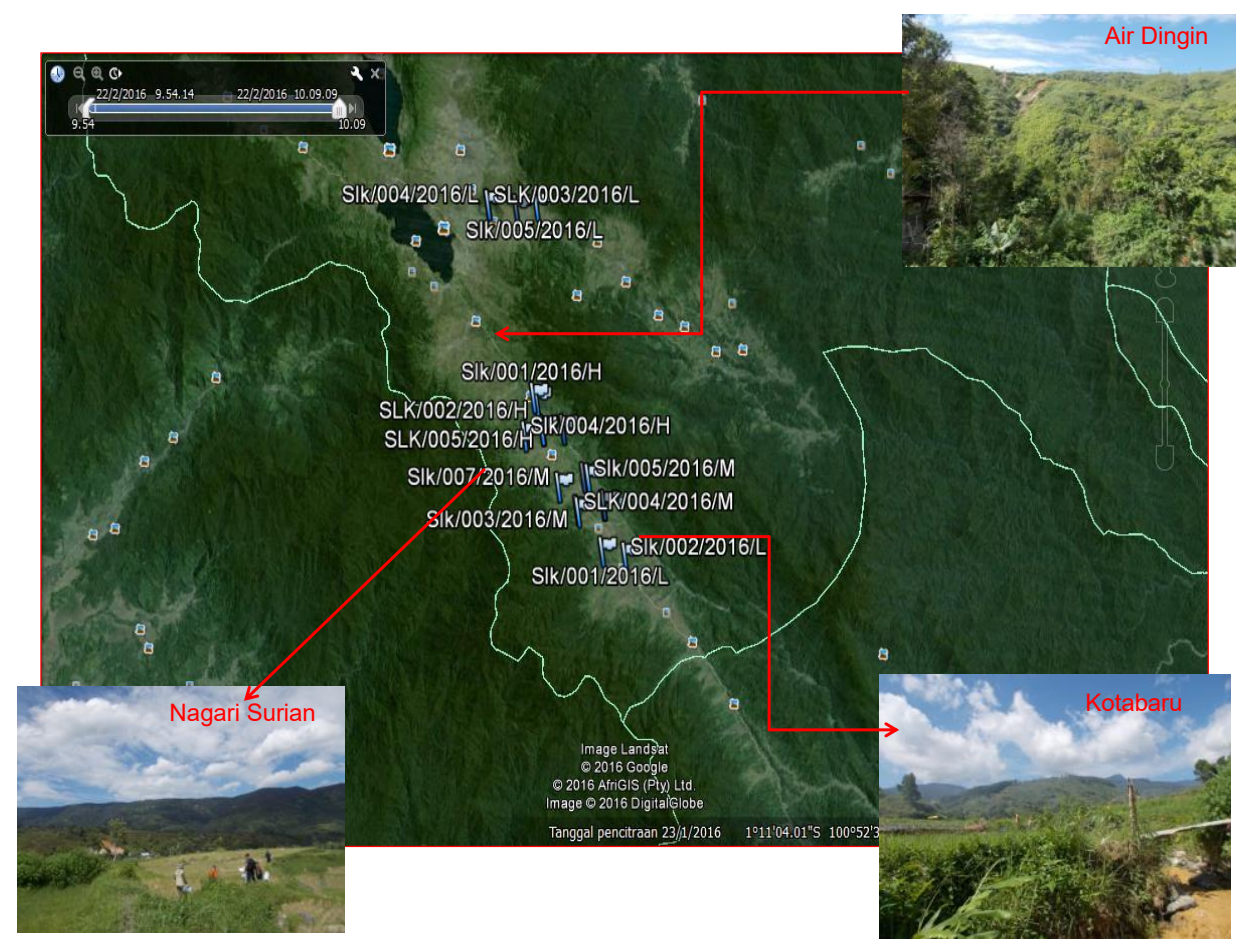

Gambar 1. Kegiatan pengambilan conto sedimen sungai aktif dilakukan di tiga wilayah di Kabupaten Solok, Provinsi Sumatera Barat

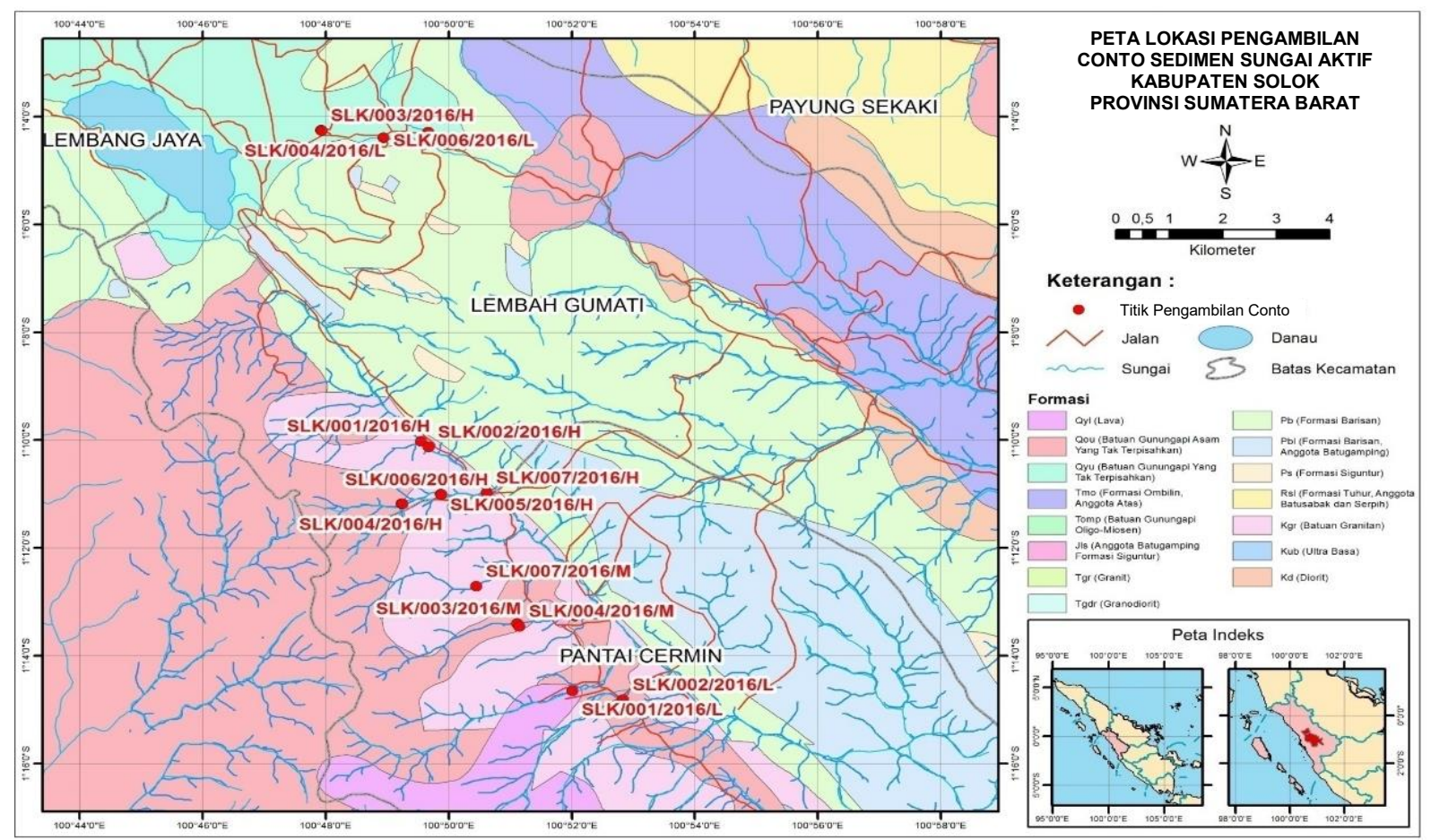

Gambar 2. Peta lokasi pengambilan conto sedimen sungai aktif Kabupaten Solok, Provinsi Sumatera Barat 


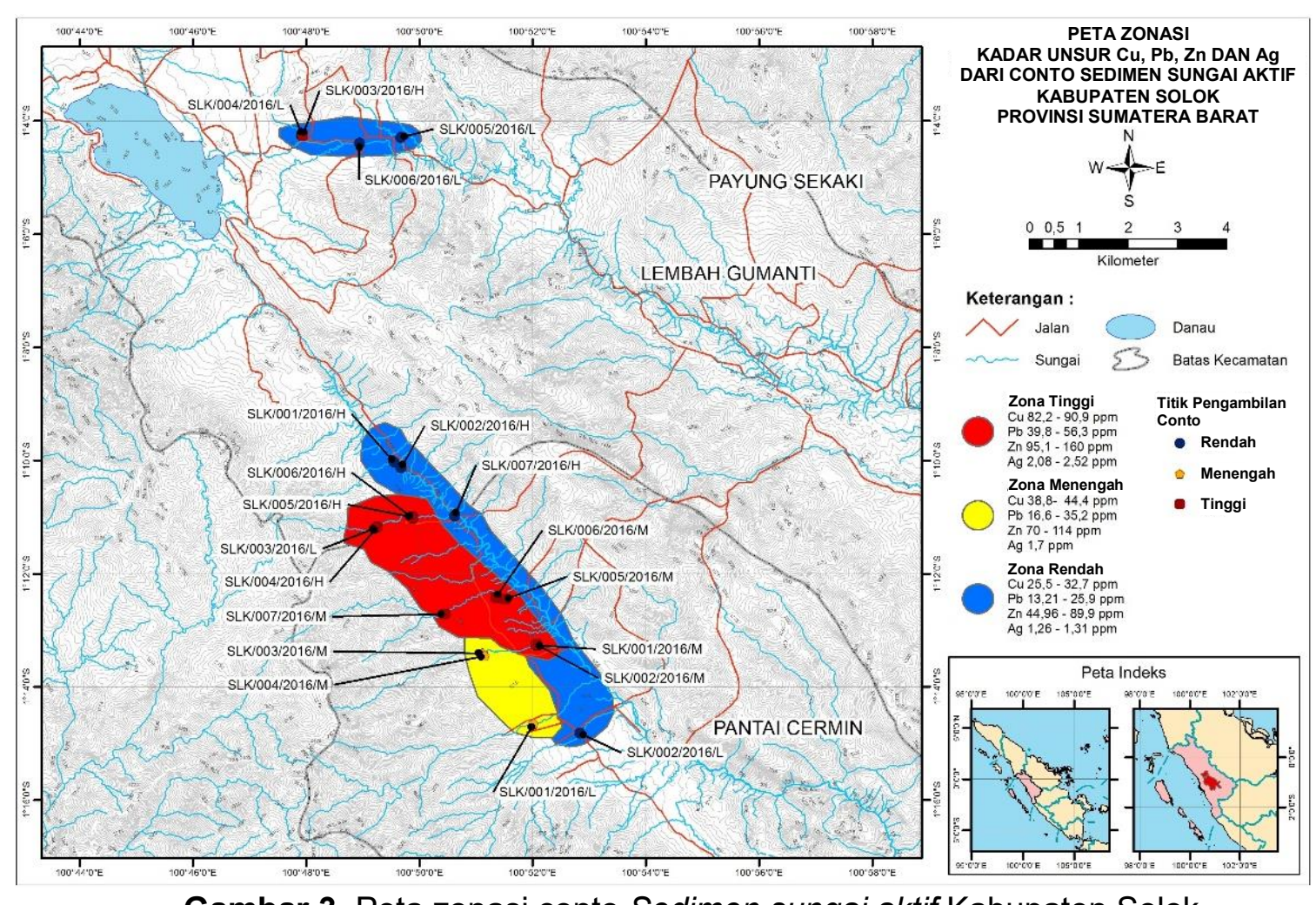

Gambar 3. Peta zonasi conto Sedimen sungai aktif Kabupaten Solok, Provinsi Sumatera Barat

\section{Permercontoan Sedimen Sungai Aktif}

Kegiatan pemercontoan sedimen sungai aktif di lapangan dapat dibagi menjadi beberapa tahapan yaitu:

\section{Pengambilan Conto}

Pengambilan conto merupakan tahapan pertama dalam proses pembuatan bahan acuan baku. Salah satu prinsip yang penting dalam pengambilan conto yaitu conto harus representative, sehingga hasil analisis laboratorium dapat memberikan gambaran kandungan unsur-unsur yang terdapat di daerah tersebut.

Pengambilan conto di lapangan dilakukan secara acak dari endapan sungai aktif yang diayak menggunakan ayakan berukuran 80 mesh dan diberi nomor, berat conto lebih kurang dua $\mathrm{kg}$ sampai dengan tiga $\mathrm{kg}$ (Gambar 5 s.d. Gambar 8). Setelah itu conto dimasukkan ke dalam kantong plastik, kemudian diikat dengan baik. Jumlah lokasi yang dapat dilakukan pengambilan conto sebanyak 20 lokasi yang termasuk dalam tiga blok wilayah. Pengambilan conto sedimen sungai dengan fraksi halus dilakukan pada sungai orde satu, orde dua, dan orde tiga. Pengambilan conto dengan cara diambil langsung dari sungai aktif, menggunakan mangkok plastik. Conto yang diambil dari daerah aliran sungai aktif tidak terpengaruh oleh bahan-bahan yang berasal dari sampingnya seperti bahan runtuhan tebing sungai, bahan organik, dan pengotor lainnya (Ghazali dkk, 1990; (Davis dan Hartati, 1991).

\section{Preparasi dan Pengemasan Conto}

Kegiatan preparasi conto dengan cara mengeringkan conto di udara terbuka, sedangkan pengemasan conto yaitu conto dimasukkan ke dalam kantong plastik yang sudah di beri kode conto. Conto tersebut dikemas dengan baik, dan diberi label (lokasi conto, jenis conto, jumlah conto, serta tujuan pengiriman). Tujuan pengiriman yaitu laboratorium yang akan menganalisis conto tersebut dalam hal ini Laboratorium PSDMBP yang beralamat di Jalan Soekarno Hatta nomor 444 Bandung (Nicholson dan Budhiastuty, 1986). 


\section{MAKALAH ILMIAH}

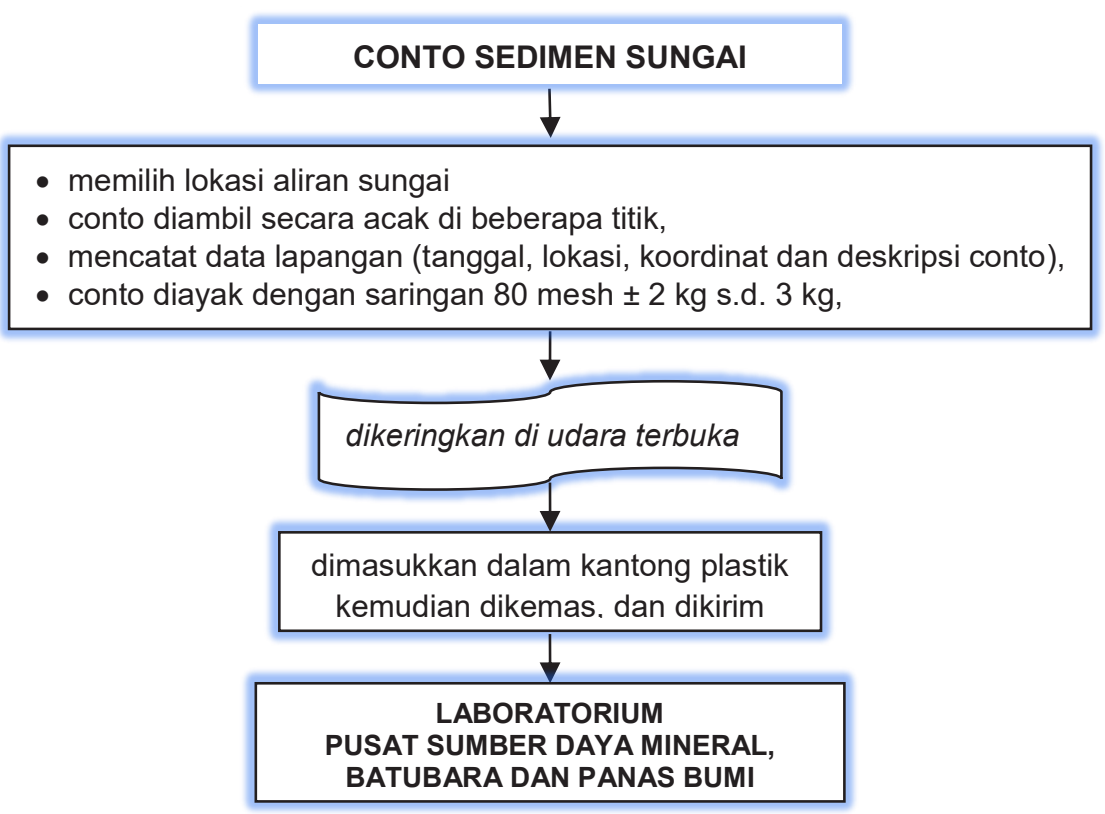

Gambar 4. Bagan alir pengambilan dan preparasi conto di lapangan

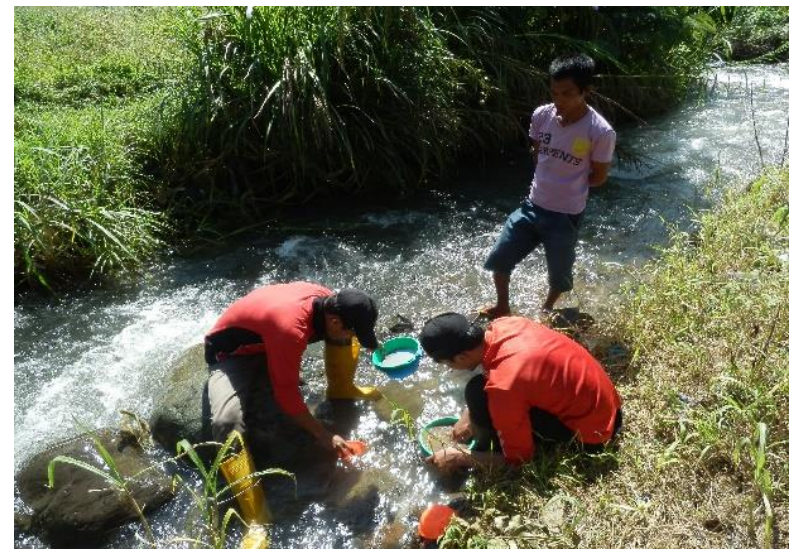

Gambar 5. Pengambilan Conto SLK/006/2016/M di Sungai Cabang Tanah Pendek

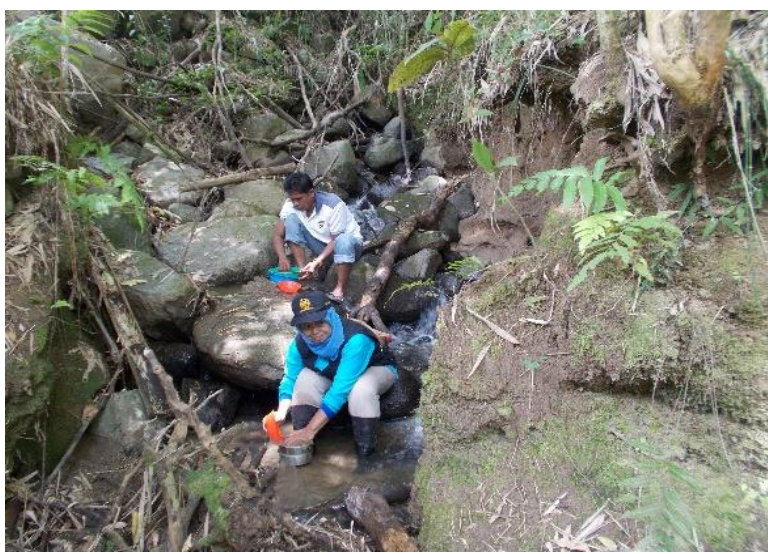

Gambar 7. Pengambilan Conto SLK/002/2016/H di Sungai Air Pinang Tebu

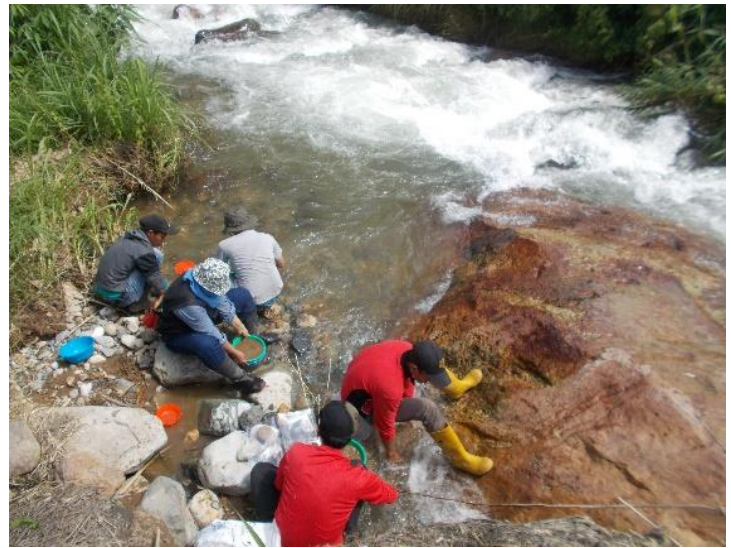

Gambar 6. Pengambilan Conto SLK/001/2016/L di Sungai Kayu Padang

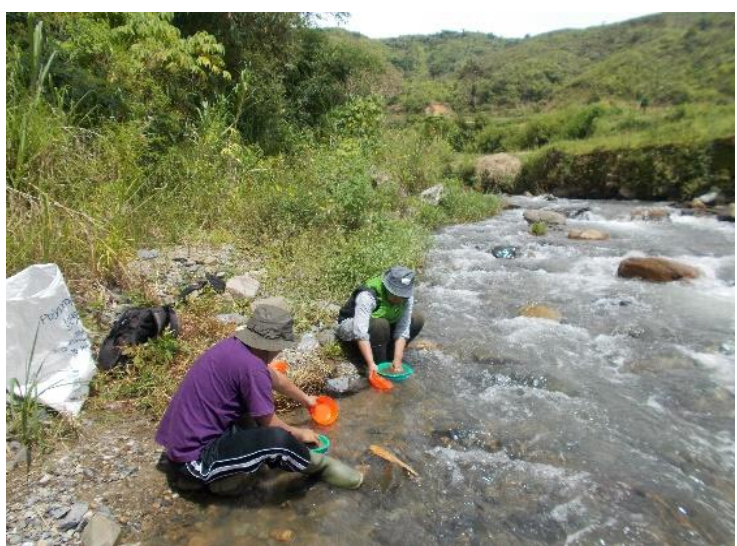

Gambar 8. Pengambilan Conto SLK/006/2016/H di Sungai Cabang Batang Baru Kapuk 
Preparasi Conto di Laboratorium

Preparasi conto di laboratorium antara lain dilakukan dengan mengeringkan, mengayak, menghaluskan, menghomogenkan dan membagi conto sampai diperoleh sejumlah conto yang diinginkan.

Conto dikeringkan sesuai masing-masing kriteria conto, dalam oven pengering suhu $105^{\circ} \mathrm{C}$ apabila conto masih dalam keadaan basah.

Conto diayak dengan cara dimasukkan dalam saringan dengan kehalusan 80 mesh, kemudian dihaluskan apabila masih terdapat conto yang butirannya masih keras dan besar butir kerakal. Conto diambil sekitar 25 gram sebanyak 10 bagian (Gambar 9) setelah diaduk dan di split dengan cara coning dan quartering. Setelah itu conto dimasukkan dalam kantong plastik yang sudah diberi kode. Conto tersebut dibawa ruang analisis untuk dianalisis kadar $\mathrm{Cu}, \mathrm{Pb}, \mathrm{Zn}$ dan Ag dengan metode Atomic Absorption Spectrophotometer (Supriyanto dan Purwanto, 2010). Hasil analisis kadar $\mathrm{Cu}, \mathrm{Pb}, \mathrm{Zn}$ dan $\mathrm{Ag}$ dijadikan dasar pengelompokan kriteria conto kadar rendah, kadar sedang dan kadar tinggi.

Conto sekitar $11 \mathrm{~kg}$ sampai dengan $13 \mathrm{~kg}$ dari ketiga kriteria conto standar tadi digerus dalam mesin Tema Mill dengan kehalusan 150 mesh sampai dengan 200 mesh (Gambar 10). Kemudian melakukan blending atau diaduk dengan mesin pengaduk (blending machine) conto dengan kehalusan 80 mesh dan conto 150 mesh sampai dengan 200 mesh selama $12 \times 8$ jam, $10 \times 8$ jam dan $21 \times 8$ jam. Ketiga conto tersebut duji homogenitasnya menggunakan metode AAS dengan parameter $\mathrm{Cu}$, hasilnya conto dengan kehalusan 80 mesh homogen (Gambar 11 dan Gambar 12). Apabila conto sudah homogen, kemudian diaduk, setelah itu dibagi rata dengan cara coning and quartering, dipisahkan masing-masing sekitar 25 gr sebanyak 10 bagian. Keenam conto standar yang sudah homogen dibagi dengan jumlah yang sama (sekitar 100 gram) pada setiap bagian dengan rotary devided, kemudian dimasukkan masing masing conto ke dalam botol conto $150 \mathrm{ml}$ (Purwanto dkk, 2007). Selanjutnya dikirimkan minimal delapan botol conto ke Laboratorium PSDMBP dan beberapa laboratorium di luar untuk uji eksternal untuk keperluan uji banding analisis (Sumadi, 2007).

\section{Pengolahan Data Statistik Validasi Metode}

Validasi metode analisis diperlukan untuk memberikan kepercayaan kepada konsumen akan hasil analisis yang dikeluarkan memiliki ketepatan dan kecermatan. Hal ini sesuai dengan persyaratan yang ada dalam ISO/IEC 17025-2005 bahwa suatu laboratorium pengujian diharuskan melakukan pengujian sesuai dengan ruang lingkup akreditasi yang telah disetujui oleh Komite Akreditasi Nasional (Dubai Accreditation Center, 2008).

\section{Presisi dan Akurasi}

Parameter yang diperlukan untuk memperoleh validitas data hasil uji adalah validitas alat uji dan validitas metode uji. Salah satu parameter yang menunjang kevalid-an suatu pengukuran adalah tingkat presisi dan akurasi dari alat dan metode uji yang dilakukan. Validasi metode uji dilakukan terhadap conto Certified Reference Material (CRM). CRM adalah bahan referensi yang bersertifikat yang sifatnya homogen dan stabil yang digunakan dalam proses pengukuran. Presisi dan akurasi dilakukan dengan melakukan pengujian berulang pada conto CRM dengan metode uji yang digunakan kemudian dibandingkan dengan nilai CRM berdasarkan sertifikat (true value). CRM yang digunakan pada pengujian ini yaitu DC 73309. Hasil presisi dan akurasi dikatakan memenuhi persyaratan apabila perolehan persentase akurasi pada kisaran antara $90 \%$ sampai dengan $110 \%$ dan prosentase presisi lebih kecil dari $5 \%$. 


\section{MAKALAH ILMIAH}

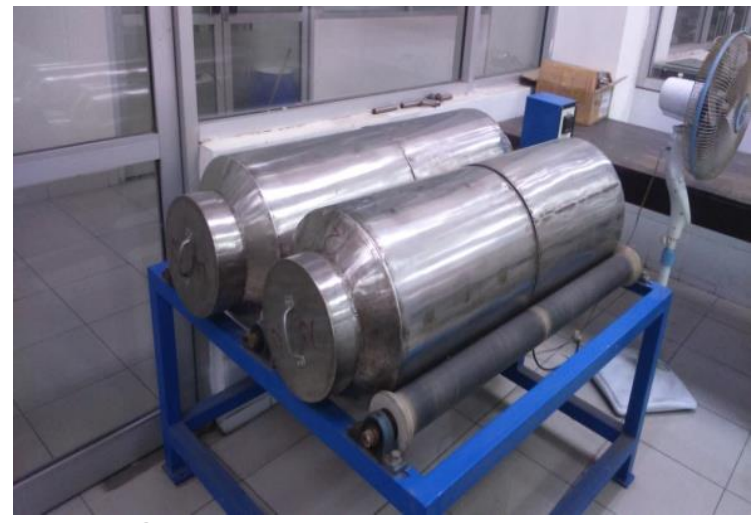

Gambar 9. Blending Machine

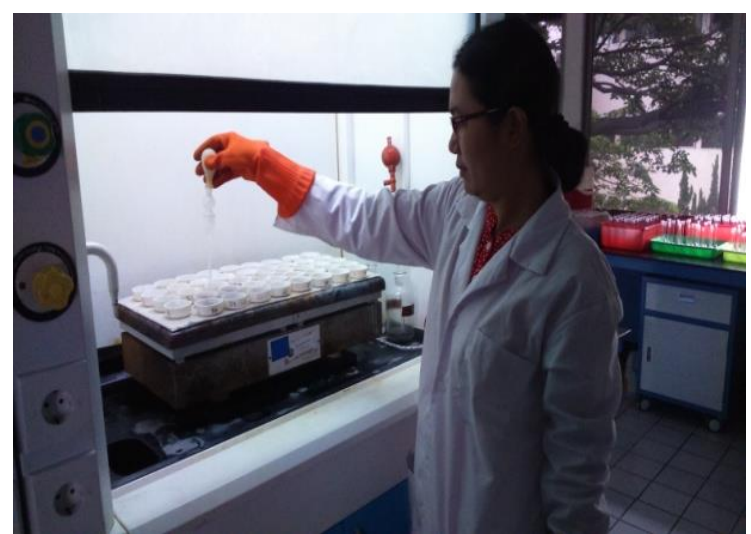

Gambar 11. Proses pelarutan conto dengan $\mathrm{HF} / \mathrm{HClO}_{4}$ menggunakan Hot Plate

\section{Batas Deteksi}

Batas deteksi (detection limit) unsur didefinisikan sebagai konsentrasi analit terendah yang masih dapat dideteksi. Batas deteksi unsur ditentukan berdasarkan perhitungan secara statistik dari kurva kalibrasi masing-masing unsur yang diperoleh. Berdasarkan kurva kalibrasi standar unsur diperoleh persamaan garis linier $y=a x+b$. Dari persamaan garis linier, dihitung besar serapan yang diperoleh $\left(\mathrm{y}^{\wedge}\right)$, harga standar deviasi penyimpangan $\left(S_{y / x}\right)$, besar serapan pada limit deteksi $\left(\mathrm{Y}_{\mathrm{I}, \mathrm{d}}\right)$ dan kadar unsur pada limit deteksi $\left(X_{I, d}\right)$. Berikut contoh perhitungan batas deteksi unsur $\mathrm{Cu}$ :

\begin{tabular}{crrr}
\hline $\mathrm{x}(\mathrm{ppm})$ & $\mathrm{y}(\mathrm{abs})$ & $\mathrm{y}^{\wedge}$ & $\left(\mathrm{y}-\mathrm{y}^{\wedge}\right)^{2}$ \\
\hline 1 & 0,1282 & 0,1487 & 0,00042 \\
\hline 2 & 0,253 & 0,2506 & 0,00001 \\
\hline 5 & 0,5898 & 0,5563 & 0,00112 \\
\hline 10 & 1,0511 & 1,0658 & 0,00022 \\
\hline & $\Sigma=$ & 0,00177 \\
\hline
\end{tabular}

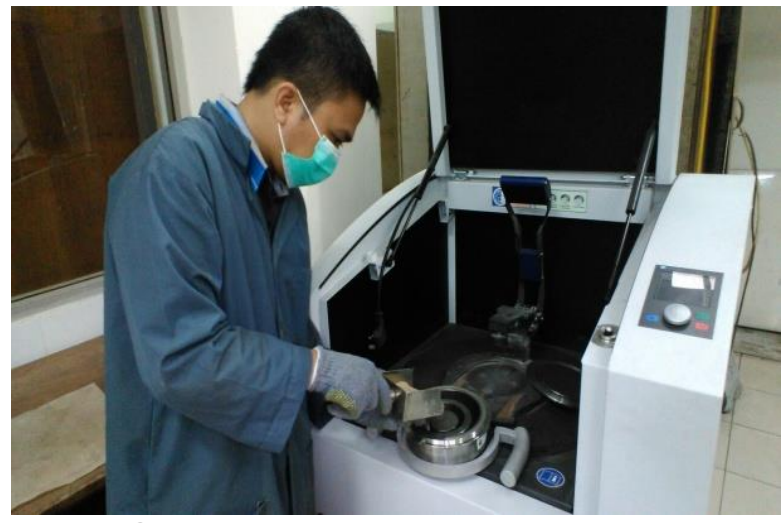

Gambar 10. Tema Mill Machine

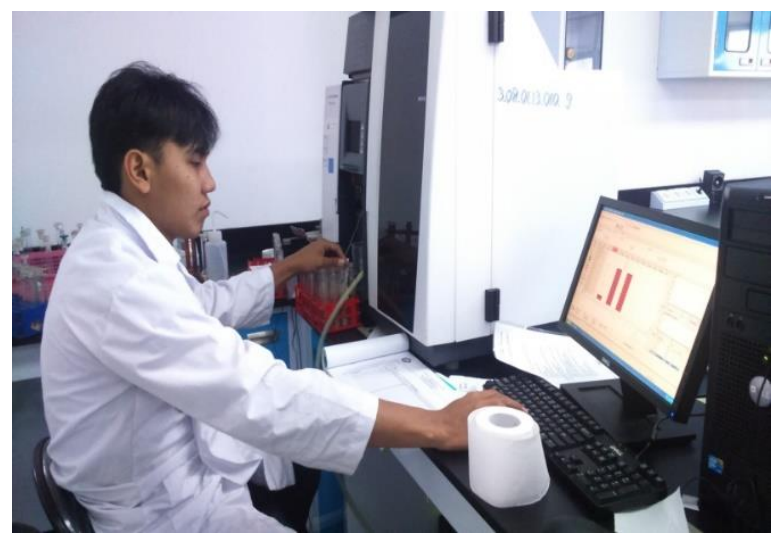

Gambar 12. Analisis conto dengan alat $A A S$

Persamaan garis linier yang diperoleh adalah $y=0,1019 x+0,0468$ dengan regresi sebesar 0,9965. Nilai standar deviasi penyimpangan $\left(\mathrm{S}_{\mathrm{y} / \mathrm{x}}\right)$ dihitung dengan formula :

$$
\begin{aligned}
& S y_{/ x}=\sqrt{\frac{\sum\left(y-y^{\wedge}\right)}{(n-2)}}=0,0297 \\
& \mathrm{Y}_{\mathrm{l}, \mathrm{d}}=\mathrm{a}+3 S_{\mathrm{y} / \mathrm{x}}=0,1359 \\
& X_{l, d}=\frac{Y_{l, d}-b}{a}=0,87 \mathrm{ppm}
\end{aligned}
$$

Dengan menggunakan formula yang sama, maka diperoleh batas deteksi untuk unsur $\mathrm{Pb}$ 0,79 ppm, Zn 0,88 ppm dan Ag 0,01 ppm.

\section{Estimasi Ketidakpastian}

Estimasi ketidakpastian merupakan salah satu faktor penting dalam penentuan validitas suatu pengukuran. Agar hasil suatu pengujian dari beberapa laboratorium dapat diperbandingkan, maka hasil analisis dari setiap laboratorium harus dilaporkan 
dengan estimasi ketidak-pastiannya. Ketidakpastian adalah parameter yang menetapkan rentang nilai yang di dalamnya ada nilai benar yang diukur. Pengertian dan kegunaan ketidakpastian pengujian dapat berbeda-beda, bergantung pada bidang kerjanya.

Dalam beberapa kasus, ketidakpastian pengujian hanya melingkupi pengulangan, namun dalam beberapa kasus lain ada pula yang melingkupi keseluruhan sumber ketidakpastian pengujian (Tuning dan Supriyanto, 2010).

\section{Uji Homogenitas}

Ada beberapa metode yang dapat digunakan untuk melakukan uji homogenitas, diantaranya adalah uji homogenitas menurut ASTM E826-85, reapproved 1996, dan uji ANOVA/uji F (Tuning dan Samin, 2012).

\section{Pelabelan Conto}

Pelabelan conto dibuat secara lengkap yang mencakup nama institusi, in-house standard, nama conto, kode conto dan urutan pembuatan dengan tulisan yang jelas dan menarik sebagai contoh nama institusi (Pusat Sumber Daya Mineral, Batubara dan Panas Bumi), nama standar (IN-HOUSE STANDARD), Jenis conto (Sedimen sungai aktif). Label ditempelkan pada botol conto ukuran $150 \mathrm{ml}$ conto.

Tata cara pelabelan conto bahan baku tersebut seperti terlihat pada Tabel 1. Secara garis besar bagan alir pembuatan bahan acuan baku dapat dilihat pada Gambar 13.

Tabel 1. Daftar Label Conto Bahan Baku

\begin{tabular}{|c|c|c|c|}
\hline No. & Kode conto & Label & Keterangan \\
\hline 1 & SS.SLK L-1 & $\begin{array}{l}\text { PUSAT SUMBER DAYA MINERAL, BATUBARA } \\
\text { DAN PANAS BUMI } \\
\text { IN-HOUSE STANDARD STREAM SEDIMENT } \\
\text { SS.SLK L-1 }\end{array}$ & $\begin{array}{l}\text { SS = stream sediment } \\
\text { SLK = Solok, Sumbar } \\
\text { L=grade low/rendah } \\
1=\text { kehalusan } 80 \text { mesh }\end{array}$ \\
\hline 2 & SS.SLK M-1 & $\begin{array}{l}\text { PUSAT SUMBER DAYA MINERAL, BATUBARA } \\
\text { DAN PANAS BUMI } \\
\text { IN-HOUSE STANDARD STREAM SEDIMENT } \\
\text { SS.SLK M-1 }\end{array}$ & $\begin{array}{l}\text { SS = stream sediment } \\
\text { SLK = Solok, Sumbar } \\
\text { L=grade low } / \text { rendah } \\
1=\text { kehalusan } 80 \text { mesh }\end{array}$ \\
\hline 3 & SS.SLK H-1 & $\begin{array}{l}\text { PUSAT SUMBER DAYA MINERAL, BATUBARA } \\
\text { DAN PANAS BUMI } \\
\text { IN-HOUSE STANDARD STREAM SEDIMENT } \\
\text { SS.SLK H-1 }\end{array}$ & $\begin{array}{l}\text { SS = stream sediment } \\
\text { SLK = Solok, Sumbar } \\
\text { L=grade low/rendah } \\
\text { 1=kehalusan } 80 \text { mesh }\end{array}$ \\
\hline 4 & SS.SLK L-2 & $\begin{array}{l}\text { PUSAT SUMBER DAYA MINERAL, BATUBARA } \\
\text { DAN PANAS BUMI } \\
\text { IN-HOUSE STANDARD STREAM SEDIMENT } \\
\text { SS.SLK L-222 }\end{array}$ & $\begin{array}{c}\text { SS = stream sediment } \\
\text { SLK = Solok, Sumbar } \\
\text { L=grade low/rendah } \\
2=\text { kehalusan } 150 \text { sd. } 200 \\
\text { mesh }\end{array}$ \\
\hline 5 & SS.SLK M-2 & $\begin{array}{l}\text { PUSAT SUMBER DAYA MINERAL, BATUBARA } \\
\text { DAN PANAS BUMI } \\
\text { IN-HOUSE STANDARD STREAM SEDIMENT } \\
\text { SS.SLK M-2 }\end{array}$ & $\begin{array}{c}\text { SLK = Solok, Sumbar } \\
\text { M = grade low/rendah } \\
\text { 2=kehalusan } 150 \text { sd. } 200 \\
\text { mesh }\end{array}$ \\
\hline 6 & SS.SLK H-2 & $\begin{array}{l}\text { PUSAT SUMBER DAYA MINERAL, BATUBARA } \\
\text { DAN PANAS BUMI } \\
\text { IN-HOUSE STANDARD STREAM SEDIMENT } \\
\text { SS.SLK H-2 }\end{array}$ & $\begin{array}{l}\text { SLK = Solok, Sumbar } \\
\text { H=grade low/rendah } \\
2=\text { kehalusan } 150 \text { sd. } 200 \\
\text { mesh }\end{array}$ \\
\hline
\end{tabular}




\section{MAKALAH ILMIAH}

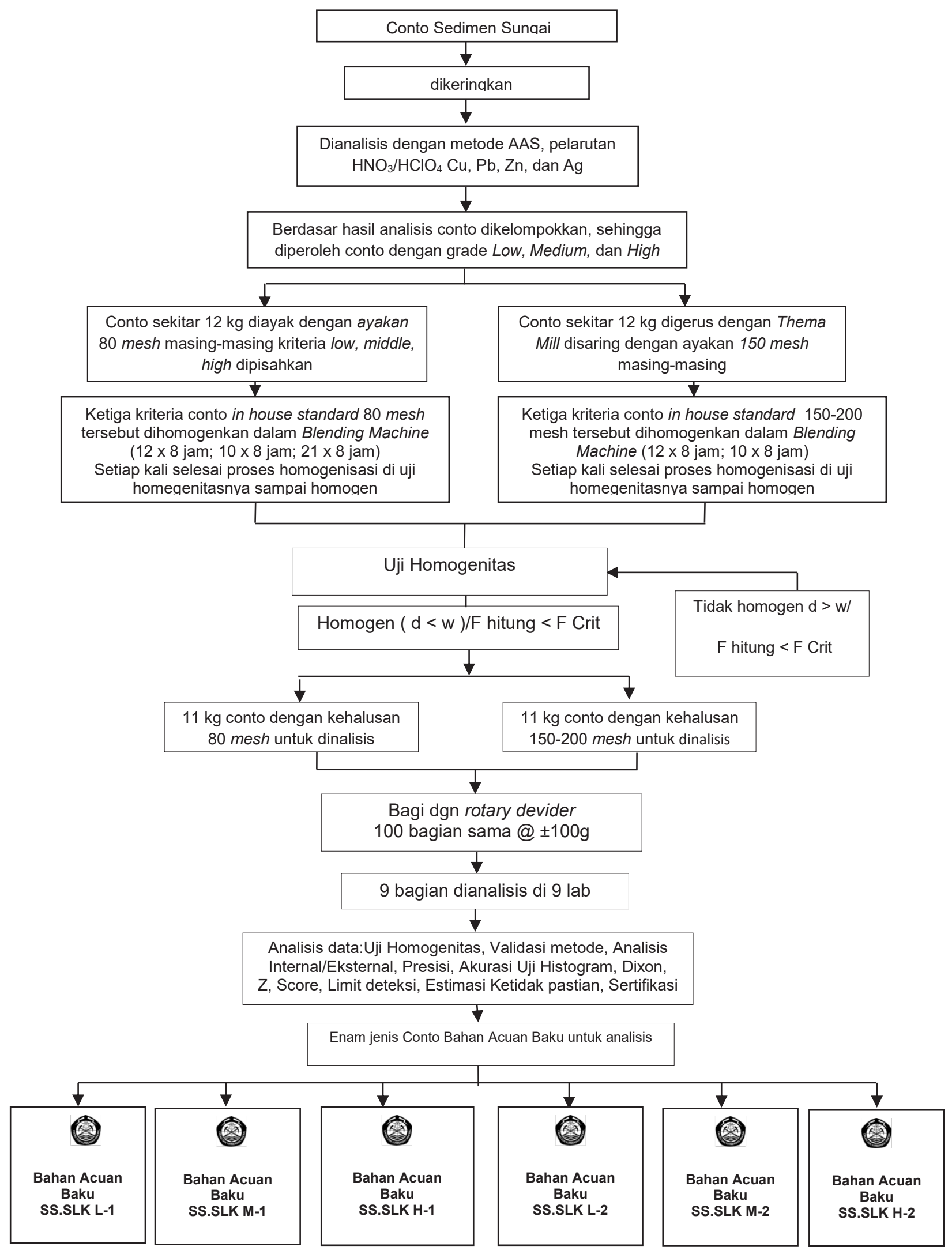

Gambar 13. Bagan alir pembuatan bahan acuan baku 


\section{HASIL DAN ANALISIS}

\section{Analisis Conto Sedimen Sungai Aktif}

Analisis conto sedimen sungai aktif-meliputi metode analisis internal dan eksternal Laboratorium Pusat Sumber Daya Mineral, Batubara dan Panas Bumi. Analisis internal dilaksanakan di Laboratorium Mineral Logam, Laboratorium PSDMBP dengan metode $A A S$, pelarutan secara partial menggunakan $\mathrm{HNO}_{3}$ (asam nitrat) dan analisis total menggunakan pelarut HF (asam fluorida), $\mathrm{HClO}_{4}$ (asam perchlorat) dan $\mathrm{HNO}_{3}$ (asam nitrat) dengan parameter $\mathrm{Cu}, \mathrm{Pb}, \mathrm{Zn}$ dan Ag. Analisis diawali dengan validasi Metode terhadap SRM (Standard Reference Material) dari NCS Cerified Reference Material SRM ini berasal dari China yaitu NCS DC 73309.

Analisis eksternal sedimen sungai aktif dilaksanakan di delapan laboratorium di luar Laboratorium PSDMBP yaitu Laboratorium Pusat Penelitian dan Pengembangan Teknologi Mineral dan Batubara (Tekmira), Institut Teknologi Bandung (ITB), Universitas Padjadjaran (UNPAD), Badan Tenaga Atom Nasional (BATAN), Pusat Survei Geologi (PSG), Geo Services (Geo Assay), Intertek Utama Services (INTERTEK) dan PT Aneka Tambang Tbk Unit Geomin (ANTAM), dengan parameter analisis unsur $\mathrm{Cu}, \mathrm{Pb}, \mathrm{Zn}$ dan $\mathrm{Ag}$.

\section{Pengolahan dan Analisis Data}

Pengolahan data internal analisis meliputi metode validasi metode, presisi dan akurasi, limit deteksi (batas deteksi), estimasi ketidakpastian dan uji homogenitas.

Laboratorium Mineral Logam PSDMBP melakukan validasi metode dengan parameter uji antara lain presisi dan akurasi, limit deteksi dan estimasi ketidakpastian.

Pada Tabel 2 disajikan hasil analisis dari conto DC 73309 dan perolehan nilai presisi dan akurasinya. Tabel tersebut menunjukkan bahwa metode uji unsur $\mathrm{Cu}$, $\mathrm{Pb}, \mathrm{Zn}$, dan Ag telah memenuhi persyaratan dengan akurasi berada di kisaran 95,64 sampai dengan $103,13 \%$ dan presisi lebih kecil dari 5\% untuk unsur $\mathrm{Cu}$ dan $\mathrm{Ag}$, sedangkan presisi untuk unsur $\mathrm{Pb}$ dan $\mathrm{Zn}$ masih di atas $5 \%$ karena perhitungan presisi yang digunakan adalah:

$$
\text { presisi }=\sqrt{\frac{\sum \Delta^{2}}{n-1}}
$$

Dimana:

$\Delta=$ selisih antara hasil analisis dengan nilai sebenarnya (sertifikat)

$\mathrm{n}=$ jumlah pengukuran (Purwanto, dkk, 2007)

Karena nilai kadar unsur $\mathrm{Pb}$ dan $\mathrm{Zn}$ besar (ratusan ppm), dengan perhitungan di atas dan jumlah pengukuran yang kurang banyak, maka nilai presisi yang dihasilkan akan besar.

Pada pengujian ini, estimasi ketidakpastian melalui pendekatan bottom up menggunakan diagram cause-effect. Sumber-sumber ketidakpastian yang dipertimbangkan pada pengujian pembuatan bahan baku untuk $\mathrm{Cu}, \mathrm{Pb}, \mathrm{Zn}$, dan $\mathrm{Ag}$ antara lain larutan standar induk dan kalibrasi, kurva kalibrasi, recovery, preparasi conto, presisi dan linieritas. Hasil perhitungan estimasi ketidakpastian conto ditampilkan pada Tabel 3.

Uji homogenitas dilakukan terhadap conto SS.SLK-L1, SS.SLK-M1, SS.SLK-H1, SS.SLK-L2, SS.SLK-M2, dan SS.SLK-H2. Conto tersebut setelah diblending, kemudian diambil 10 titik conto secara acak, setelah itu dianalisis unsur $\mathrm{Cu}$ sebagai parameter uji secara duplo (a, b). Pada Tabel 4 ditampilkan hasil pengujian unsur Cu dari tiap-tiap conto.

Kegiatan pembuatan bahan baku untuk $\mathrm{Cu}$, $\mathrm{Pb}, \mathrm{Zn}$ dan Ag menghasilkan enam macam conto baku dengan tiga kriteria dan dua jenis tingkat kehalusan, untuk conto baku kehalusan 80 mesh kriteria rendah dengan kode SS.SLK-L1 sebanyak 32 botol, kriteria sedang dengan kode SS.SLK-M1 sebanyak 39 botol, dan kriteria tinggi dengan kode SS.SLK-H1 sebanyak 32 botol sedangkan standar kehalusan 150 mesh sampai 
dengan 200 mesh kriteria rendah dengan kode SS.SLK-L2 sebanyak 34 botol, kriteria sedang dengan kode SS.SLK-M2 sebanyak 37 botol, dan kriteria tinggi dengan kode
SS.SLK-H2 sebanyak 32 botol, masingmasing seberat sekitar 100 gram. Kemasan conto baku seperti terlihat pada Gambar 14 dan Gambar 15.

Tabel 2. Hasil akurasi dan presisi metode uji menggunakan CRM NCS DC 73309

\begin{tabular}{ccccc}
\hline Unsur & $\begin{array}{c}\text { Kadar unsur sertifikat } \\
(\mathbf{p p m})\end{array}$ & $\begin{array}{c}\text { Kadar unsur pengukuran } \\
(\mathbf{p p m})\end{array}$ & $\begin{array}{c}\text { Akurasi } \\
\mathbf{( \% )}\end{array}$ & Presisi (\%) \\
\hline $\mathrm{Cu}$ & $79 \pm 3$ & $77,38 \pm 1,19$ & 97,94 & 2,10 \\
\hline $\mathrm{Pb}$ & $636 \pm 22$ & $649,75 \pm 8,71$ & 102,16 & 17,09 \\
\hline $\mathrm{Zn}$ & $373 \pm 14$ & $356,75 \pm 5,75$ & 95,64 & 18,30 \\
\hline $\mathrm{Ag}$ & $3,2 \pm 0,4$ & $3,3 \pm 0,27$ & 103,13 & 0,29 \\
\hline
\end{tabular}

Tabel 3. Estimasi ketidakpastian hasil analisis conto bahan acuan baku

\begin{tabular}{cccccc}
\hline No & Nama Conto & $\mathrm{Cu}(\mathrm{ppm})$ & $\mathrm{Pb}(\mathrm{ppm})$ & $\mathrm{Zn}(\mathrm{ppm})$ & $\mathrm{Ag}(\mathrm{ppm})$ \\
\hline 1 & SS.SLK-L1 & $25,5 \pm 3,14$ & $13.21 \pm 1,4$ & $44,96 \pm 5,92$ & $1,26 \pm 0,22$ \\
\hline 2 & SS.SLK-M1 & $38,8 \pm 4,78$ & $16,6 \pm 1,8$ & $70,05 \pm 9,2$ & $1,7 \pm 0,29$ \\
\hline 3 & SS.SLK-H1 & $82,2 \pm 12,94$ & $39,8 \pm 4,21$ & $95,1 \pm 12,53$ & $2,08 \pm 0,36$ \\
\hline 4 & SS.SLK-L2 & $32,7 \pm 4,02$ & $25,9 \pm 4,41$ & $89,9 \pm 11,76$ & $1,31 \pm 0,23$ \\
\hline 5 & SS.SLK-M2 & $44,4 \pm 7,1$ & $35,2 \pm 6$ & $114 \pm 14,9$ & $1,7 \pm 0,3$ \\
\hline 6 & SS.SLK-H2 & $90,9 \pm 14,5$ & $56,3 \pm 9,57$ & $160 \pm 20,91$ & $2,52 \pm 0,44$ \\
\hline
\end{tabular}

Tabel 4. Data hasil pengujian unsur Cu dari tiap-tiap conto di Laboratorium PSDMBP

\begin{tabular}{|c|c|c|c|c|c|c|c|c|c|c|c|c|}
\hline \multirow[t]{2}{*}{ Conto } & \multicolumn{2}{|c|}{$\begin{array}{c}\text { SS.SLK-L1 } \\
\text { (ppm) }\end{array}$} & \multicolumn{2}{|c|}{$\begin{array}{c}\text { SS.SLK-M1 } \\
(p p m)\end{array}$} & \multicolumn{2}{|c|}{$\begin{array}{c}\begin{array}{c}\text { SS.SLK-H1 } \\
(p p m)\end{array} \\
\end{array}$} & \multicolumn{2}{|c|}{$\begin{array}{c}\begin{array}{c}\text { SS.SLK-L2 } \\
(p p m)\end{array} \\
\end{array}$} & \multicolumn{2}{|c|}{$\begin{array}{c}\text { SS.SLK-M2 } \\
\text { (ppm) }\end{array}$} & \multicolumn{2}{|c|}{$\begin{array}{c}\text { SS.SLK-H2 } \\
\text { (ppm) }\end{array}$} \\
\hline & a & b & a & b & a & b & a & b & a & b & a & b \\
\hline 1 & 5,67 & 251 & 8,49 & 37,77 & 6,99 & 86,20 & 4,09 & 33,77 & 6,40 & 46,5 & 6,22 & 6,69 \\
\hline 2 & & & 88 & 7,84 & 6,65 & 85 & & 33,27 & & & 5,22 & \\
\hline 3 & 8 & & 5 & & 94 & & 4 & 1 & 0 & & 50 & 35 \\
\hline 4 & & & & & 9 & & & & & & 80 & 36 \\
\hline 5 & 47 & 2 & 78 & 38 & 26 & 87 & 46 & 36 & 20 & 61 & 95,47 & 97,17 \\
\hline 6 & 17 & 25,14 & 37,62 & 38,42 & 36,91 & 86,92 & 21 & 32,62 & 45,74 & 46,96 & 97,57 & 95,78 \\
\hline 7 & 84 & 25,16 & 37,86 & 38,14 & 87,05 & 87,04 &, 53 & 32,54 & 46,54 & 46,02 & 97,12 & 96,12 \\
\hline 8 & 09 & 25 & 38,41 & 37,65 & 6,71 & 86 , & 74 & 33,29 & 46,67 & 46,68 & 97,46 & 95,33 \\
\hline & & &, 77 & & & & & 33,55 & & & 97,87 & 95,18 \\
\hline & 5,09 & 25,42 & 37,92 & 38,23 & 86,39 & 86,26 & 32,37 & 33,81 & 45,89 & 46,78 & 96,48 & 96,24 \\
\hline
\end{tabular}

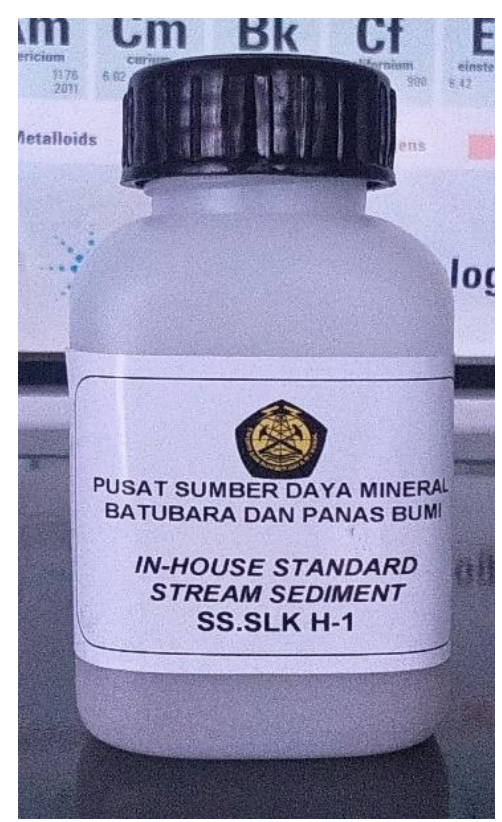

Gambar 14. Conto bahan baku analisis dengan kriteria tinggi 


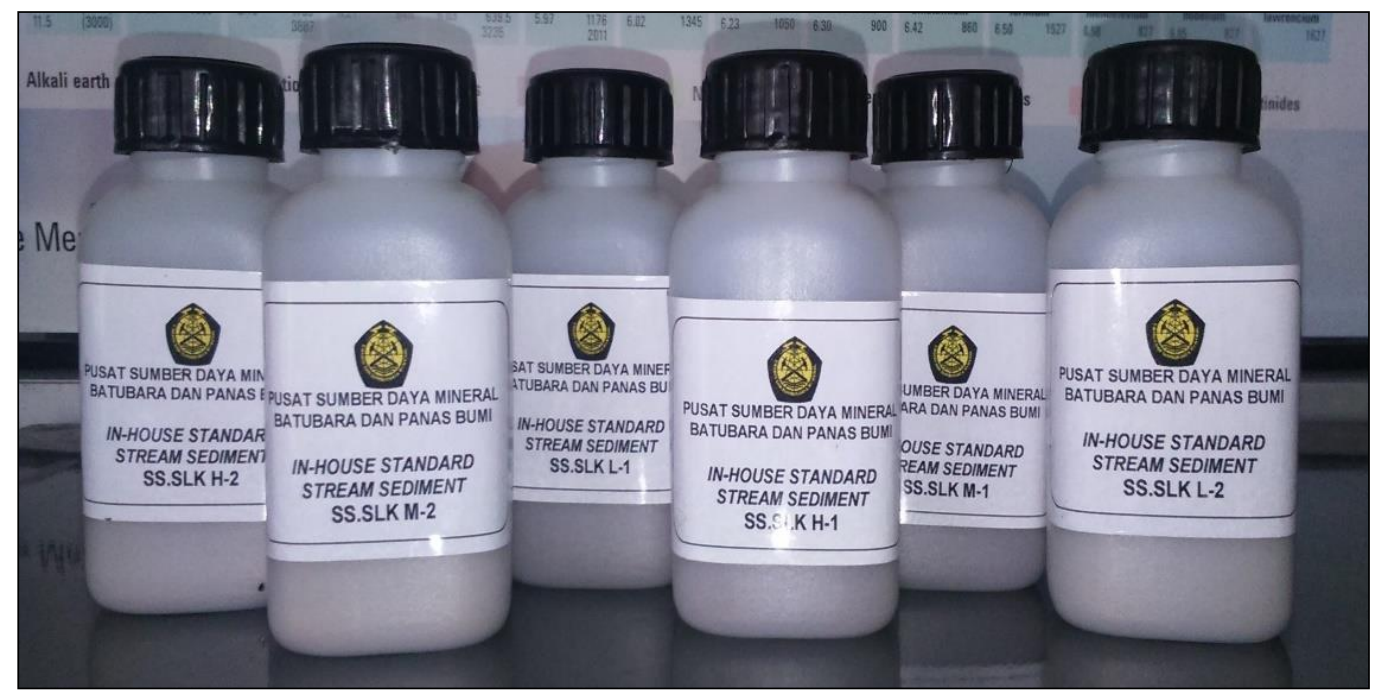

Gambar 15. Kemasan conto bahan baku dengan enam kriteria dan berbeda kehalusannya, yaitu kode conto SS.SLK-L1, SS.SLK-M1, SS.SLK-H1, SS.SLK-L2, SS.SLK-M2, SS.SLK-H2

\section{Pembahasan}

Pembuatan bahan baku berdasarkan pada kadar unsur yang paling stabil yakni tembaga $(\mathrm{Cu})$ berhasil diperoleh conto bahan baku dengan kriteria rendah, sedang dan tinggi.

Pengambilan conto bahan baku di wilayah Nagari Air dingin, Kecamatan Lembah Gumanti dan wilayah Nagari Surian, Wilayah Nagari Kota Baru, Kecamatan Pantai Cermin, Kabupaten Solok, Provinsi Sumatera Barat, tepat sesuai sasaran, karena mengacu pada hasil penelitian Suprapto (2014) dalam tesis berjudul Penentuan Daerah Potensi Mineralisasi Besi-Tembaga-Timbal-Seng dengan Metode Integrasi Data Geokimia dan Geologi Berbasis Spasial di Kabupaten Solok, Provinsi Sumatera Barat. Hasil analisis kimia menunjukkan bahwa kadar Cu bervariasi dari rendah (25 ppm), sedang (40 ppm) dan tinggi (90 ppm).

Berdasarkan perhitungan statistik, validitas metode uji AAS yang digunakan Laboratorium Mineral Logam PSDMBP untuk conto dengan parameter $\mathrm{Cu}, \mathrm{Pb}, \mathrm{Zn}$, dan Ag sebagian besar mempunyai tingkat akurasi dan presisi yang baik. Nilai akurasi dan presisi yang dihasilkan memenuhi syarat yang ditetapkan (akurasi 95\% sampai dengan 105\% dan akurasi lebih kecil dari 5\%). Namun presisi untuk kadar
$\mathrm{Pb}$ dan $\mathrm{Zn}$ kurang baik (lebih besar dari 5\%), meskipun masih masuk dalam kisaran yang tertera dalam sertifikat, hal ini dimungkinkan adanya kontaminasi pada saat pelarutan sehingga hasilnya menjadi lebih besar.

Batas deteksi alat $A A S$ untuk kadar $\mathrm{Cu}, \mathrm{Pb}$, $\mathrm{Zn}$, dan $\mathrm{Ag}$ berdasarkan perhitungan masing-masing sebesar 0,87 ppm; 0,79 ppm; 0,88 ppm dan 0,01 ppm. Sehingga standar kerja larutan yang dibuat untuk metode pengujian ini masih valid karena standar terendah yang digunakan untuk pembuatan kurva kalibrasi standar dari $\mathrm{Cu} / \mathrm{Pb} / \mathrm{Zn}$ (1 ppm) dan Ag (0,1 ppm).

Metode pengujian $A A S$ dilakukan dalam beberapa tahapan yang berperan dalam hasil analisis yang diperoleh yang disebut sumber ketidakpastian. Sumber-sumber ketidakpastian dalam metode pengujian ini antara lain larutan standar masing-masing unsur, kurva kalibrasi standar, preparasi/pelarutan, recovery, presisi dan linearitas. Nilai ketidakpastian ini merupakan kisaran nilai kadar unsur yang masih dapat diterima dari nilai yang sebenarnya.

Pengujian homogenitas conto dilakukan dengan dua metode pengujian yang umum digunakan dalam uji profisiensi, yaitu uji homogenitas menurut ASTM E826-85, reapproved 1996 dan uji ANOVA. 
Berdasarkan hasil dua metode pengujian tersebut, keenam conto (SS.SLK-L1, SS.SLK-M1， SS.SLK-H1， SS.SLK-L2, SS.SLK-M2, dan SS.SLK-H2) telah homogen.

Conto yang telah homogen kemudian dikirim ke beberapa laboratorium uji lain untuk dilakukan perbandingan hasil yang diperoleh dari conto sedimen sungai tersebut. Dari hasil analisis beberapa laboratorium tersebut kemudian dibandingkan dengan metode uji histogram, uji Dixon, dan uji z-score. Hasil analisis yang diperoleh dari semua laboratorium menunjukkan hasil yang baik untuk unsur $\mathrm{Cu}, \mathrm{Pb}$ dan $\mathrm{Zn}$, akan tetapi untuk unsur $\mathrm{Ag}$, hasil analisisnya beragam dan banyak yang berada di bawah batas deteksi alat yang digunakan oleh beberapa laboratorium tersebut. Sehingga unsur Ag tidak dapat dilakukan uji banding dengan perhitungan statistik. Keberagaman hasil analisis $\mathrm{Ag}$ ini dimungkinkan karena kadar unsur Ag dalam conto yang dikirim relatif rendah (Tabel 5 . s.d. Tabel 10.).

Tabel 5. Hasil Analisis Conto SS.SLK-L1 dari sembilan laboratorium

\begin{tabular}{lrrrr}
\hline \multirow{2}{*}{ Lab } & \multicolumn{4}{c}{ SS.SLK-L1 } \\
\cline { 2 - 5 } & $\begin{array}{c}\mathbf{C u} \\
(\mathbf{p p m})\end{array}$ & $\begin{array}{c}\mathbf{P b} \\
(\mathbf{p p m})\end{array}$ & $\begin{array}{c}\mathbf{Z n} \\
(\mathbf{p p m})\end{array}$ & $\begin{array}{c}\text { Ag } \\
(\mathbf{p p m})\end{array}$ \\
\hline PSDMBP & 25,0 & 13,5 & 43,00 & 1,30 \\
\hline Geoservices & 29,0 & 10,0 & 49,00 & 0,50 \\
\hline BATAN & 22,5 & 10,5 & 37,50 & $<0,02$ \\
\hline Tekmira & 19,5 & 6,5 & 42,00 & 1,50 \\
\hline PSG & 26,0 & 7,0 & 46,50 & $<0,04$ \\
\hline ITB & 28,5 & 21,0 & 63,50 & 37,50 \\
\hline UNPAD & 43,1 & 17,1 & 41,35 & 12,95 \\
\hline Intertek & 27,0 & 13,0 & 66,00 & $<1,00$ \\
\hline ANTAM & 22,0 & 27,5 & 59,50 & $-1,58$ \\
\hline
\end{tabular}

Tabel 6. Hasil Analisis Conto SS.SLK-M1 dari sembilan laboratorium

\begin{tabular}{lrrrr}
\hline \multirow{2}{*}{ Lab } & \multicolumn{4}{c}{ SS.SLK-M1 } \\
\cline { 2 - 5 } & $\begin{array}{c}\mathbf{C u} \\
(\mathbf{p p m})\end{array}$ & $\begin{array}{c}\mathbf{P b} \\
(\mathbf{p p m})\end{array}$ & $\begin{array}{c}\mathbf{Z n} \\
(\mathbf{p p m})\end{array}$ & $\begin{array}{c}\mathbf{A g} \\
(\mathbf{p p m})\end{array}$ \\
\hline PSDMBP & 38,0 & 17,00 & 67,0 & 1,75 \\
\hline Geoservices & 45,5 & 12,50 & 74,0 & 0,00 \\
\hline BATAN & 34,0 & 11,50 & 56,0 & $<0,02$ \\
\hline Tekmira & 33,0 & 5,50 & 60,0 & 1,00 \\
\hline PSG & 40,0 & 7,00 & 70,0 & $<0,04$ \\
\hline ITB & 43,5 & 29,00 & 92,0 & 46,50 \\
\hline UNPAD & 52,6 & 17,45 & 60,6 & 11,40 \\
\hline Intertek & 41,0 & 13,00 & 97,0 & $<1,00$ \\
\hline ANTAM & 38,0 & 32,50 & 52,5 & $-1,10$ \\
\hline
\end{tabular}

Tabel 7. Hasil Analisis Conto SS.SLK-H1 dari sembilan laboratorium

\begin{tabular}{lrrrr}
\hline \multirow{2}{*}{ Lab } & \multicolumn{4}{c}{ SS.SLK-H1 } \\
\cline { 2 - 5 } & $\begin{array}{c}\mathbf{C u} \\
(\mathbf{p p m})\end{array}$ & $\begin{array}{c}\mathbf{P b} \\
(\mathbf{p p m})\end{array}$ & $\begin{array}{c}\mathbf{Z n} \\
(\mathbf{p p m})\end{array}$ & $\begin{array}{c}\mathbf{A g} \\
(\mathbf{p p m})\end{array}$ \\
\hline PSDMBP & 80,50 & 39,0 & 91,0 & 2,15 \\
\hline Geoservices & 95,50 & 35,5 & 101,0 & 0,50 \\
\hline BATAN & 69,00 & 35,0 & 87,5 & $<0,02$ \\
\hline Tekmira & 80,00 & 34,5 & 95,0 & 1,00 \\
\hline PSG & 83,00 & 30,0 & 99,5 & $<0,04$ \\
\hline ITB & 94,00 & 48,0 & 112,5 & 29,50 \\
\hline UNPAD & 101,85 & 43,7 & 79,8 & 15,60 \\
\hline Intertek & 97,00 & 50,0 & 96,0 & $<1,00$ \\
\hline ANTAM & 86,00 & 53,0 & 89,5 & $-1,56$ \\
\hline
\end{tabular}

Tabel 8. Hasil Analisis Conto SS.SLK-L2 dari sembilan laboratorium

\begin{tabular}{lrrrr}
\hline \multirow{2}{*}{ Lab } & \multicolumn{4}{c}{$\mathbf{S S . S L K - L 2}$} \\
\cline { 2 - 5 } & $\begin{array}{c}\mathbf{C u} \\
(\mathbf{p p m})\end{array}$ & $\begin{array}{c}\mathbf{P b} \\
(\mathbf{p p m})\end{array}$ & $\begin{array}{c}\mathbf{Z n} \\
(\mathbf{p p m})\end{array}$ & $\begin{array}{l}\text { Ag } \\
(\mathbf{p p m})\end{array}$ \\
\hline PSDMBP & 32,0 & 26,5 & 86,00 & 1,35 \\
\hline Geoservices & 36,5 & 11,9 & 99,50 & 0,50 \\
\hline BATAN & 24,0 & 14,5 & 83,00 & $<0,02$ \\
\hline Tekmira & 25,5 & 11,0 & 85,00 & 1,50 \\
\hline PSG & 32,5 & 11,5 & 120,50 & $<0,04$ \\
\hline ITB & 35,5 & 40,0 & 110,50 & 13,00 \\
\hline UNPAD & 37,1 & 22,4 & 73,45 & 11,85 \\
\hline Intertek & $<50,0$ & 50,0 & 110,00 & $<5,00$ \\
\hline ANTAM & 30,0 & 45,5 & 80,00 & $-0,35$ \\
\hline
\end{tabular}

Tabel 9. Hasil Analisis Conto SS.SLK-M2 dari sembilan laboratorium

\begin{tabular}{lrrrr}
\hline \multirow{2}{*}{ Lab } & \multicolumn{4}{c}{ SS.SLK-M2 } \\
\cline { 2 - 5 } & $\begin{array}{c}\mathbf{C u} \\
(\mathbf{p p m})\end{array}$ & $\begin{array}{c}\mathbf{P b} \\
\mathbf{( p p m )}\end{array}$ & $\begin{array}{c}\mathbf{Z n} \\
\mathbf{( p p m )}\end{array}$ & $\begin{array}{l}\mathbf{A g} \\
(\mathbf{p p m})\end{array}$ \\
\hline PSDMBP & 43,50 & 36,00 & 109,00 & 1,75 \\
\hline Geoservices & 52,00 & 18,40 & 124,50 & 0,50 \\
\hline BATAN & 31,50 & 22,50 & 106,00 & $<0,02$ \\
\hline Tekmira & 40,00 & 19,00 & 115,00 & 1,50 \\
\hline PSG & 46,50 & 18,50 & 89,50 & $<0,04$ \\
\hline ITB & 52,00 & 42,00 & 136,50 & 17,50 \\
\hline UNPAD & 48,65 & 32,35 & 91.85 & 11,65 \\
\hline Intertek & $<50,00$ & 90,00 & 150,00 & $<5,00$ \\
\hline ANTAM & 44,50 & 54,00 & 114,50 & $-0,04$ \\
\hline
\end{tabular}

Tabel 10. Hasil Analisis Conto SS.SLK-H2 dari sembilan laboratorium

\begin{tabular}{lrrrr}
\hline \multirow{1}{*}{ Lab } & \multicolumn{4}{c}{ SS.SLK-H2 } \\
\cline { 2 - 5 } & $\begin{array}{c}\mathbf{C u} \\
(\mathbf{p p m})\end{array}$ & $\begin{array}{c}\mathbf{P b} \\
(\mathbf{p p m})\end{array}$ & $\begin{array}{c}\mathbf{Z n} \\
(\mathbf{p p m})\end{array}$ & $\begin{array}{l}\text { Ag } \\
(\mathbf{p p m})\end{array}$ \\
\hline PSDMBP & 89,0 & 57,5 & 153,00 & 2,60 \\
\hline Geoservices & 107,5 & 34,8 & 176,50 & 0,50 \\
\hline BATAN & 64,5 & 36,0 & 165,00 & $<0,02$ \\
\hline Tekmira & 90,0 & 37,0 & 160,00 & 2,50 \\
\hline PSG & 96,0 & 34,5 & 251,00 & $<0,04$ \\
\hline ITB & 107,5 & 64,0 & 174,00 & 19,00 \\
\hline UNPAD & 98,9 & 56,9 & 122,35 & 14,80 \\
\hline Intertek & 100,0 & 70,0 & 200,00 & $<5,00$ \\
\hline ANTAM & 97,5 & 78,5 & 183,00 & 0,81 \\
\hline
\end{tabular}


Berdasarkan uji histogram, hasil analisis conto sedimen sungai untuk unsur $\mathrm{Cu}, \mathrm{Pb}$ dan $\mathrm{Zn}$ juga beragam. Kemudian diuji dengan metode uji Dixon, dihasilkan beberapa hasil analisis laboratorium luar yang outlier, seperti hasil analisis $\mathrm{Cu}$ pada SS.SLK-L1 dari Laboratorium UNPAD, dan hasil analisis $\mathrm{Cu}$ pada SS.SLK-H2 dari Laboratorium BATAN.

Sama halnya dengan uji Dixon, uji z-score juga untuk mengetahui hasil analisis laboratorium mana saja yang outlier pada conto sedimen sungai aktif ini dan sebagai evaluasi kinerja pengujian dari laboratorium tersebut. Berdasarkan uji z-score ada beberapa hasil analisis laboratorium yang outlier diantaranya Laboratorium UNPAD (kadar Cu pada SS.SLK-L1), Laboratorium Intertek (kadar Pb pada SS.SLK-M2), Laboratorium BATAN (kadar $\mathrm{Cu}$ pada SS.SLK-H2), dan Laboratorium PSG (kadar $\mathrm{Zn}$ pada SS.SLK-H2). Disamping hasil analisis yang outlier, ada pula laboratorium yang hasil analisisnya masuk dalam kategori kurang baik, diantaranya Laboratorium UNPAD (kadar $\mathrm{Cu}$ pada SS.SLK-M1 dan kadar Zn pada SS.SLK$\mathrm{H} 2$ ), Laboratorium ANTAM (kadar Pb pada SS.SLK-M1), Laboratorium INTERTEK (kadar Zn pada SS.SLK-M1), Laboratorium ITB (kadar Zn pada SS.SLK-H1), dan Laboratorium BATAN (kadar $\mathrm{Cu}$ pada SS.SLK-M2).

\section{KESIMPULAN DAN SARAN}

\section{Kesimpulan}

Pusat Sumber Daya Mineral, Batubara dan Panas Bumi memiliki dua conto bahan baku analisis conto sedimen sungai aktif yaitu dengan kehalusan 80 mesh dan kehalusan 150 mesh sampai dengan 200 mesh, masing-masing dengan kriteria rendah, sedang dan tinggi. Parameter untuk analisis $\mathrm{Cu}, \mathrm{Pb}, \mathrm{Zn}$ dan $\mathrm{Ag}$ dengan kode conto SS.SLK-L1, SS.SLK-M1 dan SS.SLK-H1 untuk conto bahan baku dengan kehalusan 80 mesh, sedangkan kode conto SS.SLKL2, SS.SLK-M2 dan SS.SLK-H2 untuk conto bahan baku dengan kehalusan 150 mesh sampai dengan 200 mesh.
Conto bahan baku dikemas dalam botol plastik, dengan berat masing-masing 100 gram sebanyak 101 botol untuk conto dengan kehalusan 80 mesh dan 101 botol dengan kehalusan 150 mesh sampai dengan 200 mesh.

Tersedianya bahan baku dapat menjamin mutu dan akurasi hasil analisis pengujian logam dasar (base metal) dalam conto sedimen sungai aktif.

Data hasil analisis conto bahan baku yang dibuat Laboratorium PSDMBP, memberikan hasil dan presisi yang baik, dengan metode yang valid.

Pembuatan bahan baku akan membantu peraihan akreditasi dalam ruang lingkup endapan sungai, tanah dan batuan dengan parameter $\mathrm{Cu}, \mathrm{Pb}, \mathrm{Zn}$ dan $\mathrm{Ag}$, sesuai dengan yang dipersyaratkan Komite Akreditasi Nasional dalam SNI ISO/IEC 17025-2008 tentang ketertelusuran pengukuran dalam jaminan mutu hasil analisis.

\section{Saran}

Kegiatan eksplorasi geokimia di Pusat Sumber Daya Mineral, Batubara dan Panas Bumi dapat terus ditingkatkan, karena laboratorium telah mempunyai bahan baku yang dapat dijadikan acuan untuk analisis sedimen sungai aktif yang akurat.

Pembuatan bahan baku untuk komoditi lainnya perlu dilakukan agar dapat meningkatkan kinerja laboratorium dan terhindar dari ketergantungan pada negara lain yang memproduksi bahan acuan analisis tersebut.

\section{UCAPAN TERIMA KASIH}

Penulis mengucapkan terima kasih kepada rekan-rekan di Laboratorium PSDMBP khususnya Laboratorium Mineral Logam yang telah membantu dalam proses pembuatan bahan acuan baku ini, sehingga dapat diselesaikan dengan lancar. Ucapan terima kasih kami sampaikan juga kepada Dewan Redaksi yang telah membantu dalam penulisan makalah ini. 


\section{MAKALAH ILMIAH}

\section{DAFTAR PUSTAKA}

Davis, A. E. dan Hartati, R. D. 1991. The Preparation of Quality Control Sample for The Analysis of Sample from Southern Sumatra Geological and Mineral Exploration Project. Bandung.

Dubai Accreditation Center 2008. Guidance for Statistical Evaluation of Interlaboratory Proficiency Testing, Dubai Municipality, (3), Hal. 10.

Ghazali, S. A., Suganda, E. dan Johnson, C. C. 1990. Methods and Techniques Used in Southern Sumatra Geochemical Mapping Programme. Bandung.

Nicholson., Budhiastuty 1986. Sample Preparation and Methods of Chemical Analysis used by The Northern Sumatra Geochemical and Mineral Exploration Project. Bandung.

Purwanto, A., Supriyanto, C. dan Samin, P. 2007. Validasi Pengujian $\mathrm{Cr}$, Cu dan $\mathrm{Pb}$ Dengan Metode Spektrometri Serapan Atom, in Prosiding PPI PDIPTN. Yogyakarta: Pusat Teknologi Akselerator dan Proses Bahan BATAN, Hal. 151-158.

Sumadi, K. 2007. Bahan Acuan untuk Uji Kompetensi, Homogenitas Bahan Acuan, Uji Stabilitas Conto Acuan, Kompetensi Kemampuan Pengujian Antar Analis. Bandung.
Suprapto, S. J. 2014. Penentuan Daerah Potensi Mineralisasi Besi-TembagaTimbal-Seng dengan Metode Integrasi Data Geokimia dan Geologi Berbasis Spasial di Kabupaten Solok, Provinsi Sumatra Barat. Universitas Padjajaran.

Supriyanto, C. dan Purwanto, A. 2010. Validasi Metode Spektrometri Serapan Atom pada Analisis Logam Berat $\mathrm{Cr}, \mathrm{Cu}, \mathrm{Cd}, \mathrm{Fe}, \mathrm{Pb}, \mathrm{Zn}$ dan $\mathrm{Ni}$ dalam Contoh Uji Air Laut, in Prosiding PPI - PDIPTN. Yogyakarta: Pusat Teknologi Akselerator dan Proses Bahan - BATAN, Hal. 115-122.

Tuning, S. dan Samin, S. 2012. Uji homogenitas dan stabilitas kandidat srm natrium zirkonat dengan metode xrf, in Prosiding PPI - PDIPTN. Yogyakarta: Pusat Teknologi Akselerator dan Proses Bahan BATAN, Hal. 176-183.

Tuning, S. and Supriyanto, C. 2010. Estimasi Ketidakpastian Hasil Pengujian $\mathrm{Cu}, \mathrm{Cr}$ Dan $\mathrm{Fe}$ Dalam Contoh Sedimen Dengan Metode FAas, in Prosiding PPI - PDIPTN. Yogyakarta: Pusat Teknologi Akselerator dan Proses Bahan BATAN, Hal. 139-146.

$\begin{array}{ll}\text { Diterima } & : 17 \text { Juli } 2017 \\ \text { Direvisi } & : \text { 03 Agustus } 2017 \\ \text { Disetujui } & : 30 \text { November } 2017\end{array}$

